\title{
TRATAMENTO DE ÁGUA SUBTERRÂNEA CONTAMINADA COM COMPOSTOS ORGANOCLORADOS USANDO FERRO ELEMENTAR E O REAGENTE DE FENTON
}

\author{
Tatiana Langbeck de Arruda* \\ Centro de Pesquisas de Paulínia, Rhodia Poliamida \& Especialidades Ltda, Fazenda São Francisco, s/n, 13140-000 \\ Paulínia - SP, Brasil \\ Wilson F. Jardim \\ Departamento de Química Analítica, Instituto de Química, Universidade Estadual de Campinas, CP 6154, 13084-971 \\ Campinas - SP, Brasil
}

Recebido em 1/9/06; aceito em 15/2/07; publicado na web em 30/7/07

\begin{abstract}
TREATMENT OF GROUNDWATER CONTAMINATED WITH CHLORINATED COMPOUNDS USING ELEMENTAL IRON AND FENTON'S REAGENT. The remediation of groundwater containing organochlorine compounds was evaluated using a reductive system with zero-valent iron, and the reductive process coupled with Fenton's reagent. The concentration of the individual target compounds reached up to $400 \mathrm{mg} \mathrm{L}^{-1}$ in the sample. Marked reductions in the chlorinated compounds were observed in the reductive process. The degradation followed pseudo-first-order kinetics in terms of the contaminant and was dependent on the sample contact time with the solid reducing agent. An oxidative test with Fenton's reagent, followed by the reductive assay, showed that tetrachloroethylene was further reduced up to three times the initial concentration. The destruction of chloroform, however, demands an additional treatment.
\end{abstract}

Keywords: zero valent iron; Fenton's reagent; chlorinated compounds.

\section{INTRODUÇÃO}

A problemática da contaminação de águas subterrâneas por compostos químicos tem intensificado a busca por tecnologias capazes de abater tais poluentes ${ }^{1}$. A contaminação por organoclorados, por exemplo, ainda é um desafio para os pesquisadores, por se tratarem de compostos de alta persistência e toxicidade conhecida. Neste caso, a aplicação de métodos não-destrutivos, como a adsorção sobre carvão ativado, são pouco atraentes, pois além de promoverem apenas a transferência de fase do contaminante, geram um passivo de difícil disposição². Por outro lado, os métodos destrutivos, tais como os POA (Processos Oxidativos Avançados), que envolvem a geração de radicais altamente reativos como os radicais hidroxila $(\cdot \mathrm{OH})$, são capazes de oxidar contaminantes orgânicos, gerando substâncias inócuas, tais como água, gás carbônico e íons inorgânicos ${ }^{3-6}$, ou ainda transformá-los em compostos intermediários mais biodegradáveis ${ }^{7,8}$. No entanto, grande parte dos compostos organoclorados são, sob o aspecto cinético, dificilmente destruídos em um sistema oxidativo e, neste ponto, o ferro elementar aparece como uma ferramenta poderosa na remediação de águas contaminadas com compostos halogenados?.

Com base nestas informações, o principal objetivo deste trabalho foi buscar um tratamento destrutivo alternativo para as estações de tratamento de água subterrânea contaminada com diversos organoclorados, em uma área pertencente à Rhodia, e que hoje operam com leitos de carvão ativado. $\mathrm{O}$ tratamento redutivo foi feito com ferro elementar granulado e o tratamento misto (redutivo/ oxidativo) foi feito aproveitando-se o efluente do tratamento redutivo seguido da adição de peróxido de hidrogênio.

\section{Histórico e situação atual}

Resíduos provenientes da fabricação de tetracloreto de carbo-

*e-mail: tlarruda1@gmail.com no e percloroetileno contendo, principalmente, hexaclorobenzeno (HCB) foram dispostos de maneira irregular em sítios da Baixada Santista na década de 70. Esta disposição acarretou na contaminação das águas subterrâneas, que hoje são tratadas pela Rhodia via um sistema de adsorção em leitos de carvão ativado ${ }^{10}$.

Neste processo, as águas bombeadas do aquífero para a superfície são encaminhadas para um tanque de equalização, no qual é realizado o ajuste de pH com a adição controlada de soda cáustica. A seguir, as águas passam por um filtro para remoção do material sólido em suspensão e partem para o sistema de adsorção dos contaminantes em leito contendo carvão ativado, composto por uma série de colunas em série. As águas são devolvidas ao ambiente, dentro dos padrões legais do Conselho Nacional do Meio Ambiente (CONAMA).

\section{Princípio do processo empregado}

\section{Reagente de Fenton $\left(\mathrm{H}_{2} \mathrm{O}_{2} / \mathrm{Fe}^{2+}\right)$}

Os estudos de degradação de compostos orgânicos por peróxido de hidrogênio $\left(\mathrm{H}_{2} \mathrm{O}_{2}\right)$ em solos e águas subterrâneas foram inicialmente testados para os derivados de petróleo e mais tarde, para os solventes clorados ${ }^{11}$. No entanto, o peróxido de hidrogênio sozinho não é um bom oxidante para a maioria dos compostos orgânicos. A combinação de $\mathrm{H}_{2} \mathrm{O}_{2}$ com sais de ferro (reagente de Fenton) gera radicais hidroxila, que possuem alto poder oxidante ${ }^{12}$.

$\mathrm{H}_{2} \mathrm{O}_{2}+\mathrm{Fe}^{2+} \rightarrow \mathrm{OH}^{-}+\mathrm{Fe}^{3+}+\cdot \mathrm{OH}$
$\mathrm{H}_{2} \mathrm{O}_{2}+\mathrm{Fe}^{3+} \rightarrow \mathrm{H}^{+}+\mathrm{Fe}^{2+}+\cdot \cdot \mathrm{HO}_{2}$

Estas reações são exotérmicas e promovem a formação de gás e calor ${ }^{11}$. No entanto, o processo também envolve uma série de outras reações de competição, como por ex., o excesso de íons $\mathrm{H}^{+}$ (Equação 3) ou ainda, a decomposição na presença de carbonatos ou bicarbonatos (Equações 4 e 5): 
$\mathrm{Fe}^{2+}+\mathrm{H}_{2} \mathrm{O}_{2}+2 \mathrm{H}^{+} \rightarrow \mathrm{Fe}^{3+}+2 \mathrm{H}_{2} \mathrm{O}$

$\mathrm{CO}_{3}^{2-}+\cdot{ }^{2} \mathrm{OH} \rightarrow \cdot \mathrm{CO}_{3}^{-}+\mathrm{OH}^{-}$

$\mathrm{HCO}_{3}^{-}+\cdot \mathrm{OH} \rightarrow \cdot \mathrm{CO}_{3}^{-}+\mathrm{H}_{2} \mathrm{O}$

\section{Desalogenação redutiva com ferro elementar (ferro de valência zero)}

Barreiras permeáveis reativas utilizam esse processo para degradar compostos presentes em águas subterrâneas. A tecnologia envolvendo ferro elementar vem sendo reconhecida como uma maneira eficiente e de alto custo-benefício na remoção de contaminantes ${ }^{13-14}$.

Outros metais são passíveis de degradar pesticidas via redução, como é o caso do zinco ${ }^{15}$, do alumínio ${ }^{16}$ e também do magnésio ${ }^{17}$. No entanto, o ferro é o quarto elemento mais abundante da crosta terrestre ${ }^{18}$, além de ser relativamente barato e não tóxico, o que torna interessante sua aplicação na remediação de águas subterrâneas contaminadas.

O par redox formado pelo ferro metálico em seu estado elementar, $\mathrm{Fe}^{0}$, e a forma aquosa dissolvida, $\mathrm{Fe}^{2+}$, tem um potencial padrão de redução de $-0,440 \mathrm{~V}$.

$\mathrm{Fe}^{2+}+2 \mathrm{e}^{-} \rightarrow \mathrm{Fe}^{0}$

Isto faz do ferro elementar um poderoso agente redutor para uma variedade de substâncias, entre elas, íons hidrogênio, carbonato, sulfato, nitrato e oxigênio. Haletos de alquila também podem ser reduzidos pelo ferro. Na presença de um doador de prótons, como por ex., a água, eles podem sofrer desalogenação redutiva ${ }^{16}$ :

$\mathrm{RX}+2 \mathrm{e}^{-}+\mathrm{H}^{+} \rightarrow \mathrm{RH}+\mathrm{X}^{-}$

O potencial padrão de redução para a semi-reação 7 varia entre $+0,5 \mathrm{a}+1,5 \mathrm{~V}$ em $\mathrm{pH} 7,0$. Assim, a diferença de potencial entre as reações 6 e 7 indica um favorecimento termodinâmico sob uma variedade de condições. A reação 8 , por ex., mostra a oxidação do ferro com um haleto de alquila.

$\mathrm{Fe}^{0}+\mathrm{RX}+\mathrm{H}^{+} \rightarrow \mathrm{Fe}^{2+}+\mathrm{RH}+\mathrm{X}^{-}$

$\mathrm{Na}$ ausência de oxidantes fortes, outras duas semi-reações podem fazer par com a reação (6) para produzir uma reação de corrosão espontânea na presença de água. O oxigênio dissolvido, quando presente, é o agente oxidante preferencial (Equação 9), resultando em rápida corrosão (Equação 10).

$\mathrm{O}_{2}+2 \mathrm{H}_{2} \mathrm{O}+4 \mathrm{e}^{-} \rightarrow 4 \mathrm{OH}^{-}$

$2 \mathrm{Fe}^{0}+\mathrm{O}_{2}+2 \mathrm{H}_{2} \mathrm{O} \rightarrow 2 \mathrm{Fe}^{2+}+4 \mathrm{OH}$

A oxidação de $\mathrm{Fe}^{2+}$ pelo $\mathrm{O}_{2}$ também leva à formação de hidróxidos de ferro. Entretanto, a água, sozinha, pode servir como oxidante (Equação 11) e então, a corrosão acontece sob condições anaeróbias (Equação 12).

$2 \mathrm{H}_{2} \mathrm{O}+2 \mathrm{e}^{-} \rightarrow \mathrm{H}_{2}+2 \mathrm{OH}^{-}$

$\mathrm{Fe}^{0}+2 \mathrm{H}_{2} \mathrm{O} \rightarrow \mathrm{Fe}^{2+}+\mathrm{H}_{2}+2 \mathrm{OH}^{-}$

Tanto os meio aeróbios quanto anaeróbios (reações 10 e 12) resultam em aumento de $\mathrm{pH}$ em sistemas fracamente tamponados, embora o efeito seja mais pronunciado sob condições aeróbias, já que a corrosão ocorre de maneira mais rápida. $\mathrm{O}$ aumento de $\mathrm{pH}$ favorece a formação de precipitados de hidróxido de ferro que podem eventualmente formar uma camada superficial no metal e ini- bir sua dissolução. Pode-se concluir com estas explicações que os três principais redutores do sistema $\mathrm{Fe}^{0}-\mathrm{H}_{2} \mathrm{O}$ são o metal, o íon ferroso e o hidrogênio que resulta da corrosão.

\section{PARTE EXPERIMENTAL}

\section{Amostras utilizadas}

As amostras de água subterrânea foram coletadas em um poço de monitoramento instalado na Usina Química de Cubatão (UQC) Rhodia. Este poço, denominado PM-11, possui 5,5 $\mathrm{m}$ de profundidade (nível d'água de $0,61 \mathrm{~m}$ ) e foi escolhido para o estudo em função dos compostos que apresenta e de suas respectivas concentrações. Durante este estudo, foram utilizadas diferentes amostras coletadas na UQC, tendo em vista o elevado volume exigido nos ensaios, o tempo de preservação das amostras no laboratório e a possível perda por volatilização. Isto justifica a variação na composição química da água subterrânea nos resultados apresentados.

\section{Reagentes}

Foram empregados ferro elementar eletrolítico - OMG Américas, 100 mesh, 99,6\% e peróxido de hidrogênio, Degussa, $50 \%$.

\section{Ensaios com ferro elementar}

\section{Ensaio com recirculação}

O sistema com recirculação usado nos ensaios redutivos era composto por uma coluna de vidro preenchida com ferro elementar e um reservatório com capacidade para $1 \mathrm{~L}$ de amostra (conforme a Figura 1). As amostras eram retiradas a cada $6 \mathrm{~h}$ para análise.

\section{Ensaio com passagem única}

Nesta montagem a amostra tinha passagem única, em diferentes vazões, pela coluna de vidro contendo o ferro elementar. As amostras eram retiradas em função do volume de poro que passava pela coluna (Figura 1).

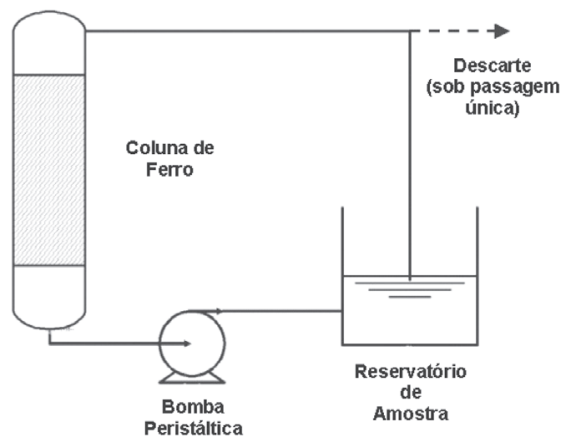

Figura 1. Esquema do sistema redutivo de destruição com reciclo da amostra. No caso de passagem única, a amostra era descartada após passar pela coluna (-----)

\section{Análises de acompanhamento realizadas}

\section{Carbono orgânico}

O carbono orgânico total (COT) foi determinado seguindo-se a metodologia padrão ISO $8245^{19}$, utilizando-se um analisador de carbono orgânico total Shimadzu TOC-5000.

Cloreto

As determinações de cloreto foram feitas por cromatografia 
iônica (Dionex, Modelo CMA-2), utilizando-se uma coluna IonPac AS9-HC. O objetivo desta medida era avaliar o índice de destruição dos compostos organoclorados, levando em consideração que o cloreto é um íon conservativo.

\section{Ferro}

A determinação de ferro foi realizada por ICP OES (espectrômetro de emissão óptica com plasma acoplado indutivamente), ARL Modelo 3410. Esse parâmetro era avaliado para verificação da concentração de ferro após o tratamento redutivo. De acordo com o CONAMA $357^{20}$, que fixa os padrões para lançamento de efluentes, o ferro pode ser lançado nos corpos d'água em até $15 \mathrm{mg} \mathrm{L}^{-1}$, enquanto pela Portaria 518 do Ministério da Saúde ${ }^{21}$, ele pode estar presente em água potável na concentração máxima de $0,3 \mathrm{mg} \mathrm{L}^{-1}$.

\section{Compostos organoclorados}

A determinação da concentração dos compostos organoclorados foi realizada por cromatografia gasosa. A quantificação seguiu um método adaptado da "Environmental Protection Agency" (EPA 600/ 54-83-052, de 1994 para os organoclorados leves e EPA 525 para os organoclorados pesados). Trabalhou-se com um GC-ECD, marca HP, modelo 6890, e uma coluna semicapilar, referência LM5 (30 m x 0,53 mm x 2,5 $\mu \mathrm{m}$; fase: $5 \%$ Fenil - 95\% Dimetilsiloxano). Após terem sido estabelecidas as condições de análise, um volume de $1 \mu \mathrm{L}$ da amostra foi injetado, utilizando-se um injetor automático marca Agilent, modelo 6890. A técnica utilizada para a determinação destes compostos em água foi extração com n-hexano, seguida da determinação por cromatografia gasosa com a utilização de um detector de captura de elétrons ${ }^{22,23}$. A Tabela 1 apresenta as condições do ensaio.

Tabela 1. Condições de análise do GC-ECD

Gás de arraste

Vazão do gás de arraste

Gás "make-up"

Vazão do gás "make-up"

Método e volume de injeção

Temperatura do injetor

Temperatura do detector

\section{RAMPA DE AQUECIMENTO}

Temperatura inicial

Tempo inicial

Programa de temperatura

Temperatura final

Tempo final

\section{RESULTADOS E DISCUSSÃO}

Antes do ensaio foi necessário conhecer o volume de vazios da coluna de ferro, ou seja, o volume de poro. Este volume corresponde ao espaço não ocupado pelas partículas de ferro. A determinação foi realizada por gravimetria, pesando-se a coluna seca preenchida com ferro, frente à mesma preenchida com água. $\mathrm{O}$ resultado corresponde a $39 \mathrm{~mL}$ de poro para cada $100 \mathrm{~mL}$ de ferro empacotado, ou seja, $39 \%$.

Após determinação do volume de poro, realizou-se um ensaio preliminar a uma vazão de $2,8 \mathrm{~mL} \mathrm{~min}^{-1}$. Os resultados, ilustrados na Figura 2, revelam que o tratamento foi eficiente para a maioria dos compostos, sendo o alvo de $50 \mu \mathrm{g} \mathrm{L}^{-1}$, exceto para clorofórmio, tetracloreto de carbono e tricloroetileno, que é de $1000 \mu \mathrm{g} \mathrm{L}^{-1}$. Observando o ensaio realizado, nota-se que apenas o clorofórmio não atinge o alvo, embora apresente uma taxa de redução de $90 \%$. Além disso, reduções superiores a $99 \%$ são observadas para tetracloreto de carbono, hexaclorobenzeno e pentaclorofenol, sendo que o hexacloroetano foi rapidamente destruído nas primeiras 6 $\mathrm{h}$ de reação, apresentando valores abaixo do limite de detecção $\left(0,1 \mu \mathrm{g} \mathrm{L}^{-1}\right)$.

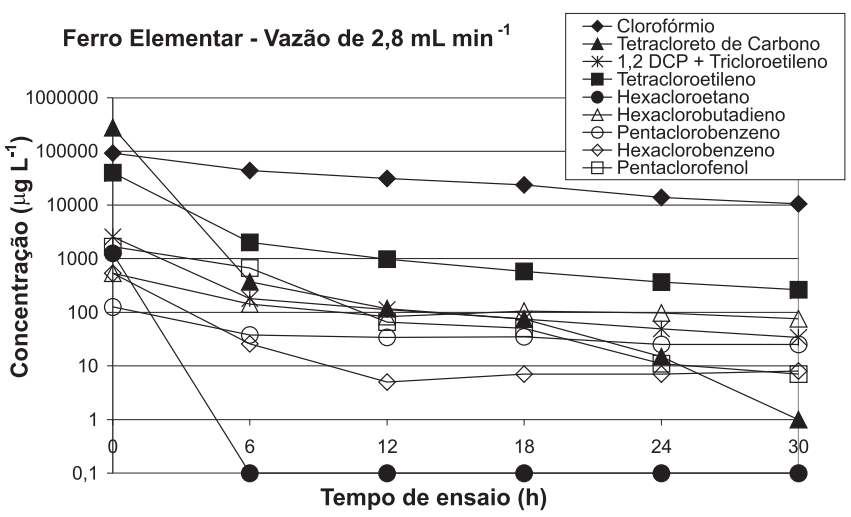

Figura 2. Redução na concentração dos compostos organoclorados durante o primeiro ensaio com ferro elementar, realizado em vazão de $2,8 \mathrm{~mL} \mathrm{~min}{ }^{-1}$, em função do tempo

Objetivando saber se o regime de escoamento é importante nesta montagem experimental, procedeu-se à realização do mesmo ensaio, porém a uma vazão duas vezes superior $\left(5,6 \mathrm{~mL} \mathrm{~min}^{-1}\right)$. O aumento da vazão provoca um aumento de turbulência no sistema e, por conseqüência, um maior cisalhamento entre as partículas. Como a desalogenação redutiva com ferro é um fenômeno superficial, o aumento da vazão poderia promover maior cisalhamento e conseqüente limpeza da superfície do ferro, o que aumentaria o rendimento na desalogenação dos contaminantes. No entanto, conforme visto na Figura 3, este mesmo aumento no regime de escoamento foi prejudicial ao processo, já que a cinética da reação é lenta. No entanto, ainda que o aumento da vazão tenha prejudicado em parte o tratamento, as taxas de redução são comparáveis ao primeiro ensaio, ou seja, superiores a $90 \%$. O regime de escoamento adotado, portanto, deve ser definido de acordo com o objetivo ou valores-alvo, ou seja, onde se pretende chegar em termos de concentração final.

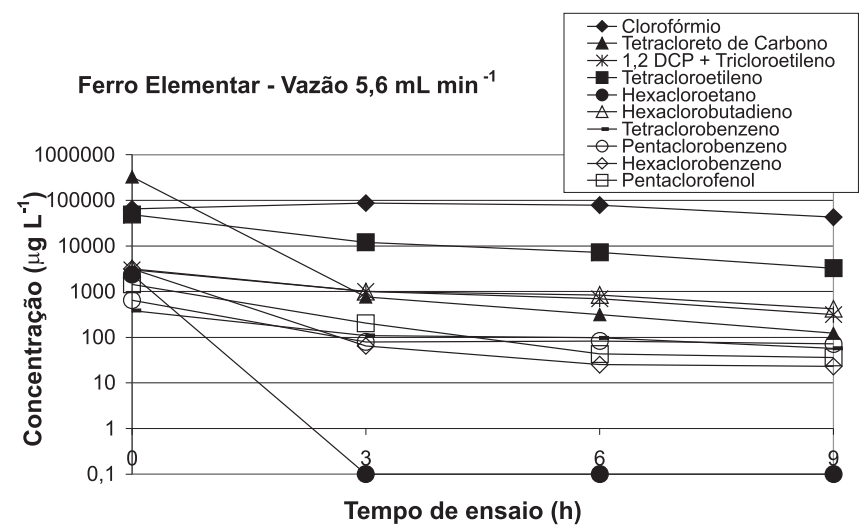

Figura 3. Redução na concentração dos compostos organoclorados durante o segundo ensaio com ferro elementar, realizado em vazão de 5,6 $\mathrm{mL} \mathrm{min}{ }^{-1}$, em função do tempo

Em ambos ensaios observou-se um aumento de $\mathrm{pH}$ durante o tratamento. Isso acontece porque a produção de íons $\mathrm{Fe}^{2+}$ é concomitante com a dos íons $\mathrm{OH}^{-}$. Como consequiência, os teores 
de ferro em solução aumentam cerca de $50 \%$ do valor original durante o ensaio, atingindo valores acima de $1000 \mathrm{mg} \mathrm{L}^{-1}$. Ainda com base nas Figuras 2 e 3, nota-se claramente para alguns compostos uma reação de pseudo-primeira ordem em relação ao substrato, especialmente nas primeiras horas de reação. Comportamento este já observado por diversos autores ${ }^{13,16,17,24}$.

Em termos de degradação, o único composto que resiste à redução é o clorofórmio, que segundo relato ${ }^{25}$ é muito recalcitrante em ambientes redutores. A situação ainda é agravada com a desalogenação do tetracloreto de carbono. Como a transferência de dois elétrons e quebra simultânea de duas ligações $\mathrm{C}-\mathrm{Cl}$ não acontece, o aumento da concentração de $\mathrm{CHCl}_{3}$ no final do teste é devido à destruição de $\mathrm{CCl}_{4}$. Já o tetracloroetileno, embora seja reduzido a taxas superiores a $90 \%$, ainda permanece distante do alvo.

Como um dos objetivos deste trabalho também foi o estudo de viabilidade técnica e econômica da tecnologia proposta, uma avaliação de desempenho do processo em passagem única se fez necessária. Foram testadas quatro vazões de tratamento, a saber: 100, 39, 10 e $1 \mathrm{~mL} \mathrm{~min}^{-1}$, sendo as amostras retiradas em função do volume de poro que passava pela coluna, neste caso 1,10 e 100 vezes o volume de poro, além da amostra inicial. As Figuras 4 e 5 ilustram os resultados obtidos para o ensaio a 100 e a $1 \mathrm{~mL} \mathrm{~min}^{-1}$.

Os resultados revelam que esse processo é limitado pela cinética da reação, uma vez que à medida que o tempo de residência aumenta, os resultados de degradação são melhores. Dessa maneira, é possível determinar o tempo de residência ótimo em função do objetivo (alvo) que se quer alcançar.

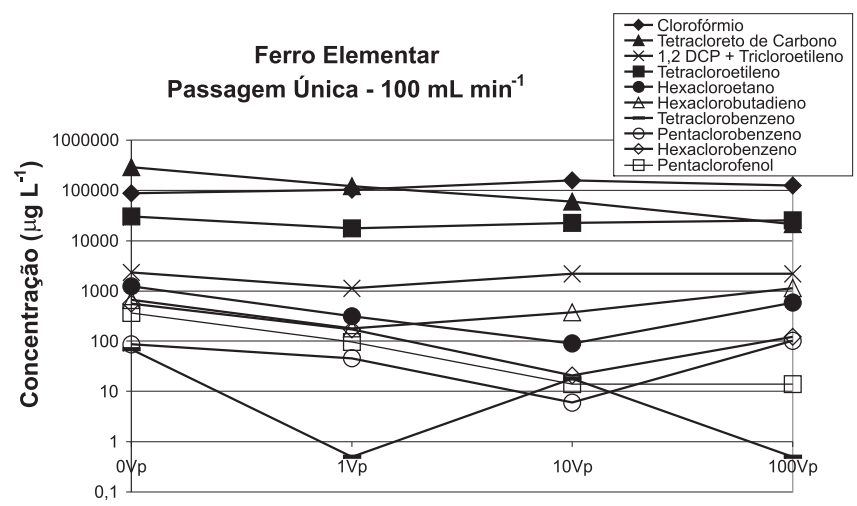

Volume de Poro $(1 \mathrm{Vp}=39 \mathrm{~mL} / 100 \mathrm{~mL})$

Figura 4. Redução na concentração dos compostos organoclorados em função do volume de poro, durante o ensaio de degradação redutiva com ferro elementar com passagem única, realizado em vazão de $100 \mathrm{~mL} \mathrm{~min} \mathrm{~m}^{-1}$

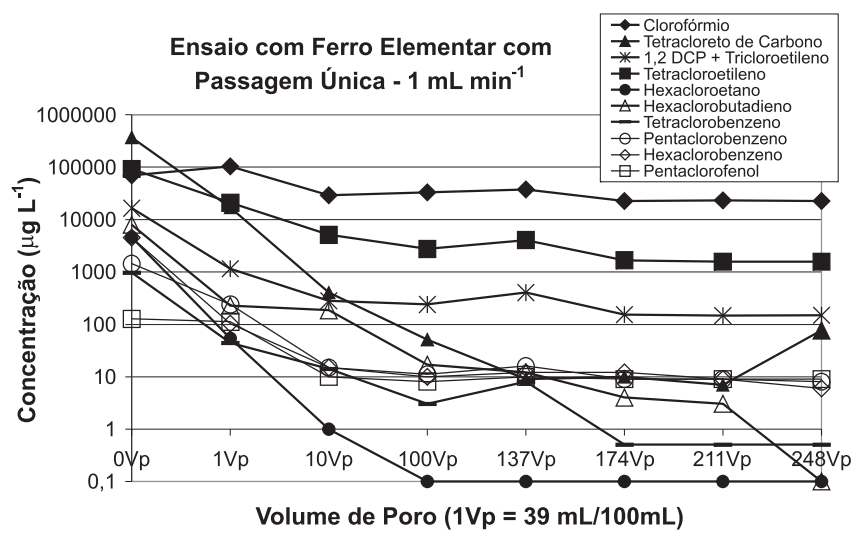

Figura 5. Redução na concentração dos compostos organoclorados em função do volume de poro, durante o ensaio de degradação redutiva com ferro elementar com passagem única, realizado em vazão de $1 \mathrm{~mL} \mathrm{~min}{ }^{-1}$
É possível observar que no ensaio de $100 \mathrm{~mL} \mathrm{~min}^{-1}$ as curvas são bastante horizontais para quase todos os compostos, o que revela a não degradação dos mesmos. No entanto, quando se avalia

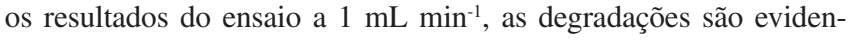
tes. Nota-se que a grande maioria dos compostos presentes na amostra vai sendo degradada até que o processo entra em regime, permanecendo em equilíbrio até que a saturação do ferro se inicie. Percebe-se que o período em que o sistema entra em regime está situado entre 10 e 100 vezes o volume de poro (10 e $100 \mathrm{Vp}$ ).

Como continuidade destes ensaios, realizou-se um teste oxidativo simples (Fenton) visando a possível destruição dos compostos que não atingiram o objetivo frente aos padrões do CONAMA: tetracloroetileno $\left(50 \mu \mathrm{g} \mathrm{L}^{-1}\right)$ e clorofórmio $(1000 \mu \mathrm{g}$ $\left.\mathrm{L}^{-1}\right)$. Realizou-se um ensaio com passagem única a $5 \mathrm{~mL} \mathrm{~min}{ }^{-1} \mathrm{e}$, após a passagem de 100 volumes de poro, admitiu-se que o sistema estava em equilíbrio e coletou-se uma amostra, a qual recebeu 100 ppm de $\mathrm{H}_{2} \mathrm{O}_{2}$. Não se adicionou ferro como catalisador, uma vez que a amostra, após passagem pela coluna já apresentava esse elemento em solução, produto da dissolução (corrosão) do $\mathrm{Fe}^{0}$ a $\mathrm{Fe}^{2+}$. Nota-se, pela Figura 6, que o clorofórmio e o tetracloroetileno ainda continuam fora dos padrões exigidos pelo CONAMA, embora o processo oxidativo tenha contribuído para uma redução significativa de até $1 / 3$ na concentração do tetracloroetileno após o ensaio oxidativo.

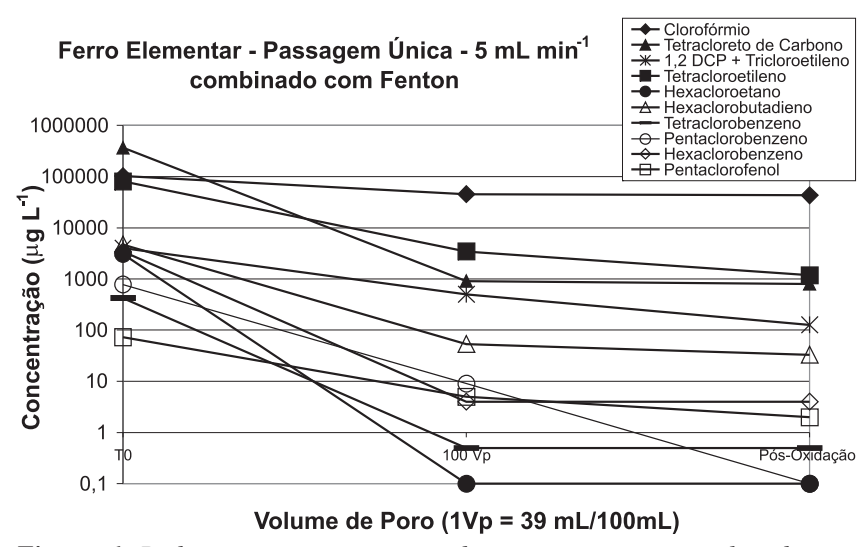

Figura 6. Redução na concentração dos compostos organoclorados em estudo durante o ensaio com ferro elementar, realizado em vazão de $5 \mathrm{~mL}$ min $^{-1}$, e reagente de Fenton, em função do tempo

\section{CONCLUSÕES}

O sistema redutivo de destruição de organoclorados presentes em amostras de água subterrânea resultou em reduções superiores a 99\% para a maioria dos compostos avaliados: tetracloreto de carbono; tricloroetileno; tricloroetano; hexacloroetano; hexaclorobutadieno; tetraclorobenzeno; pentaclorobenzeno; hexaclorobenzeno e pentaclorofenol. Tetracloroetileno e clorofórmio mostraram-se bastante recalcitrantes. A cinética de degradação observada foi de pseudo primeira ordem em relação ao contaminante e dependente do tempo de residência da amostra na coluna redutora.

O ensaio oxidativo (Fenton) usado em conjunto com o ensaio redutivo mostrou ser pouco eficiente, uma vez que não propiciou reduções adicionais atrativas frente àquelas obtidas apenas com o processo redutivo. Desta maneira, tanto para o clorofórmio como para o tetracloroetileno, entende-se que a aplicação do reagente de Fenton não apresenta vantagens adicionais, tendo como referência o custo dos insumos utilizados. Sugere-se, portanto, a manutenção de pelo menos uma coluna de carvão ativado atuando como um 
polimento na remoção destes dois compostos, caso ainda estejam em desacordo com a legislação vigente.

Cálculos realizados com base nas Estações de Tratamento de Águas Subterrâneas da Rhodia estimam ganhos de até R\$ 3 milhões (20 anos) frente ao processo atual de adsorção em carvão ativado. Dados experimentais mostram que o processo redutivo apresenta um custo-benefício bastante atrativo frente às tecnologias convencionais de transferência de fase.

Com base nestes dados, conclui-se que o ferro elementar é uma tecnologia emergente bastante promissora no tratamento de compostos clorados. Evidentemente há que se investigar mais detalhadamente algumas figuras de mérito como o tipo de ferro empregado, tempo de contato, produtos de corrosão, longevidade das colunas e/ou barreiras contendo ferro, bem como análises econômicas, as quais são caso-específicas.

\section{REFERÊNCIAS}

1. Sato, C.; Hartenstein, S. D.; Motes, W.; J. Environ. Eng. 2001, 127, 620.

2. Imamura, K.; Hiramatsu, A.; Imada, M.; Sakiyama, T.; Tanaka, A.; Yamada, Y.; Nakanishi, K.; J. Chem. Eng. Jpn. 2000, 33, 253.

3. Legrini, O.; Oliveros, E.; Braun, A. M.; Chem. Rev. 1993, 93, 671.

4. Glaze, W. H.; Lay, Y.; Kang, J.; Ind. Eng. Chem. Res. 1995, 34, 2314.

5. Nogueira, R. F. P.; Jardim, W. F.; Solar Energy 1996, 56, 471.

6. De Laat, J.; Gallard, H.; Ancelin, S.; Legube, B.; Chemosphere 1999, 39, 2693.

7. Higarashi, M. M.; Tese de Doutorado, Universidade Estadual de Campinas, Brasil, 1999.

8. Arslan, I.; Balcioglu, I. A.; J. Chem. Technol. Biotechnol. 2001, 76, 53.

9. Pereira, W. S.; Freire, R. S.; Quim. Nova 2005, 28, 130.
10. Matheus, D. R.; Dissertação de Mestrado, Instituto de Biociências, Universidade Estadual Paulista, Brasil, 1998.

11. Siegrist, R. L.; Urynowicz, M. A.; West, O. R.; Crimi, M. L.; Loew, K. S.; Principles and Practices of In Situ Chemical Oxidation using Permanganate, Battelle Press: Ohio, 2001.

12. Pera-Titus, M.; García-Molina, V.; Baños, M. A.; Giménez, J.; Esplugas, S.; Appl. Catal., B 2004, 47, 219.

13. Satapanajaru, T.; Comfort, S. D.; Shea, P. J.; J. Environ. Qual. 2003, 32, 1726

14. http://www.zerovalentirom.com, acessada em Abril 2005.

15. Sweeny, K. H.; Fischer, J. R.; US pat. 3,640,821 1972.

16. Matheson, L. J.; Tratnyek, P. G.; Environ. Sci. Technol. 1994, 28, 2045.

17. Farrel, J.; Kason, M.; Melitas, N.; Li, T.; Environ. Sci. Technol. 2000, 34, 514.

18. Lee, J. D.; Química Inorgânica Não Tão Concisa, $5^{\mathrm{a}}$ ed., Edgard Blücher Ltda: São Paulo, 1999.

19. Internacional Standardization for Organization; ISO 8245:1999 - Water Quality - Guidelines for the determination of total organic carbon (TOC) and dissolved organic carbon (DOC).

20. Resolução CONAMA $n^{\circ}$. 357; de 17 de março de 2005, - CONSELHO NACIONAL DO MEIO AMBIENTE - Dispõe sobre a classificação dos corpos de água e diretrizes ambientais para o seu enquadramento, bem como estabelece as condições e padrões de lançamento de efluentes, e dá outras providências. Revoga a Resolução CONAMA n²0, de 18 de junho de 1986.

21. MINISTÉRIO DA SAÚDE Portaria no 518 de 25 de março de 2004, Estabelece os procedimentos e responsabilidades relativos ao controle e vigilância da qualidade da água para consumo humano e seu padrão de potabilidade e dá outras providências. Revoga a Portaria nº1469, de 29 de dezembro de 2000.

22. Cienfuegos, F.; Vaitsman, D.; Análise Instrumental, Interciência: Rio de Janeiro, 2000

23. Skoog, D. A.; Holler, F. J.; Nieman, T. A.; Princípios de Análise Instrumental, $5^{\mathrm{a}}$ ed., Bookman: Porto Alegre 2002.

24. Alowitz, M. J.; Scherer, M. M.; Environ. Sci. Technol. 2002, 36, 299.

25. Elsner, M.; Dissertation of Doctor, Swiss Federal Institute of Technology, Zurich, 2002. 